\title{
Occupational Class and Incidence Rates of Cardiovascular Events in Middle Aged Men in Japan
}

\author{
Qian LI ${ }^{1,2}$, Yuko MORIKAWA ${ }^{2}$, Masaru SAKURAI ${ }^{2}$, Koshi NAKAMURA ${ }^{2}$, \\ Katsuyuki MIURA ${ }^{3}$, Masao ISHIZAKI ${ }^{4}$, Teruhiko KIDO ${ }^{5}$, Yuchi NARUSE ${ }^{6}$, \\ Yasushi SUWAZONO ${ }^{7}$ and Hideaki NAKAGAWA ${ }^{2}$
}

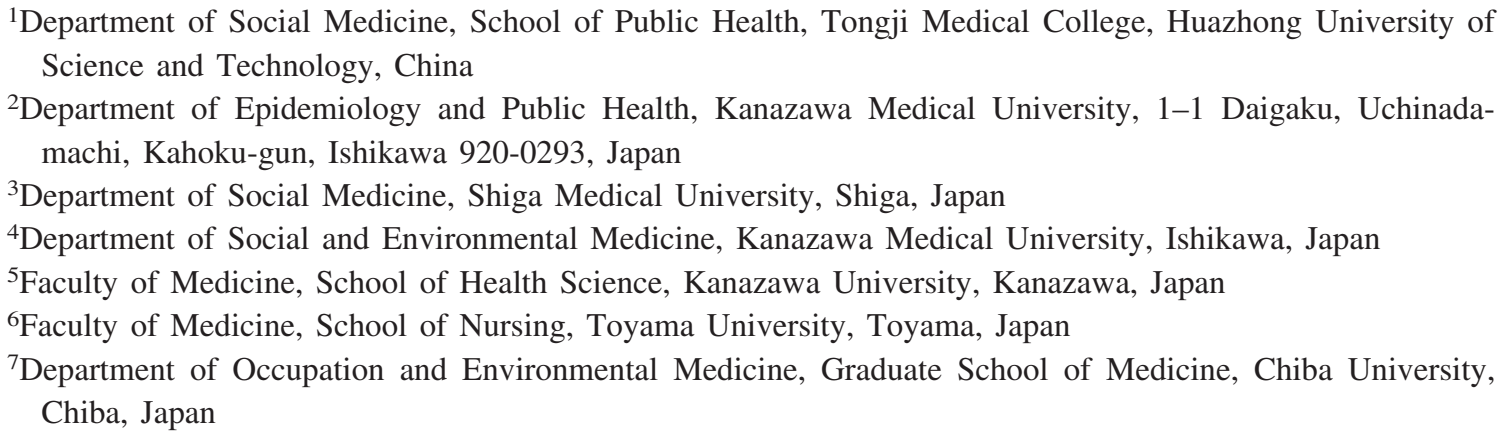

Received June 17, 2009 and accepted October 13, 2009

\begin{abstract}
We investigated whether occupational class affects the incidence of cardiovascular events in Japanese factory workers. We prospectively evaluated 1,794 male workers aged 40-59, including 632 non-manual and 1,162 manual workers, employed in a metal products factory in Japan. The hazard ratios of stroke, myocardial infarction (MI) and cardiovascular events (combined stroke, MI and sudden cardiac death) for manual workers were compared with non-manual workers as estimated by the Cox proportional hazards regression model. Among the 1,794 workers, there were 60 cardiovascular events (32 cases of stroke, 23 cases of MI and 5 cases of sudden cardiac death) with an incidence rate of 3.14 per 1,000 person-years for cardiovascular events; 1.68 for stroke and $\mathbf{1 . 2 0}$ for MI. Blood pressure and HbA1c significantly increased the risk of stroke. Body mass index and total cholesterol significantly increased the risk of MI. However, occupational class was determined not to be a risk factor for cardiovascular events. The hazard ratios of stroke, MI and cardiovascular events for manual workers compared with non-manual workers were 0.97 (95\% CI, 0.45-2.08), 0.73 (95\% CI, 0.30-1.79) and 0.92 (95\% CI, 0.53-1.61), respectively. Our study did not reveal significant occupational class inequalities in the rate of cardiovascular events. These findings are not in accordance with studies from other industrialized countries.
\end{abstract}

Key words: Stroke, Myocardial infarction, Cardiovascular events, Occupational class, Prospective study

\section{Introduction}

Studies in European countries ${ }^{1-9)}$ have revealed inequalities in mortality and incidence rate of cardiovas-

*To whom correspondence should be addressed.

E-mail: ymjr@kanazawa-med.ac.jp cular disease by occupational class, with a higher rate found in manual workers compared to non-manual workers. Widening relative health inequalities among occupational classes were also reported ${ }^{3,9)}$. Moreover, results from the Whitehall study showed a clear inverse relationship between employment grade and coronary heart disease mortality and morbidity in civil servants with rel- 
atively stable employment ${ }^{10-12)}$. The inequalities of traditional cardiovascular risk factors, such as smoking and high blood pressure, and psychosocial factors were considered to be mediating factors for such health inequalities $^{6-8,10-12)}$.

In Japan, much effort was been expended to establish biological and behavioral risk factors for stroke and myocardial infarction ${ }^{13-16)}$. Risk factors such as blood pressure, metabolic factors and smoking are not different from those of European countries and the US. However, little information on how occupational class inequalities relate to cardiovascular disease is available in Japan. A multi-center, community-based cohort study from Japan did not show significant differences in mortality from cardiovascular disease between office workers and manual workers, although there was a significant difference in mortality from stroke in the self-employed versus the employed ${ }^{17)}$.

In the present study, we analysed incidence rates of cardiovascular events including stroke, MI and sudden cardiac death in a Japanese cohort of middle-aged employees over a 12-yr period comparing manual and non-manual workers. The aim of this study was to investigate whether occupational class (manual versus non-manual workers) affected the incidence rate of cardiovascular events in Japan.

\section{Methods}

\section{Study population}

Ethics approval was obtained from the Kanazawa Medical University Epidemiological Research Ethics Committee, Ishikawa, Japan. The study population consisted of Japanese men employed by a light metal factory in Toyama Prefecture, Japan. This factory employed 4,440 male and 2,776 female employees. Among the 1,967 male workers aged 40-59, 1,920 workers who underwent a medical checkup and a questionnaire in 1994 (participation rate, 97.6\%), were enrolled as study participants. Of the 1,920 participants, 126 workers who had a history of cardiovascular events or who provided insufficient information at baseline were excluded. The cohort consisted of 1,794 men. Subjects were followed annually until they were diagnosed with a cardiovascular event or until the end of 2006.

\section{Occupational category}

Subjects were categorized as non-manual workers or manual workers according to their occupation. Information on occupation at baseline was sorted into seven categories based on the company's own classification; i.e., managers, engineers, clerks, salesmen, laborers, transport workers, and others. This was compatible with the Japanese Standard Occupational Classification ${ }^{18)}$. Employees classified as managers included workers who acted as general supervisors. Engineers were system engineers and workers engaged in developing new products. The transport workers were mainly engaged in picking up and delivering employees, driving relatively short distances to deliver materials and goods, and operating cranes. Laborers were involved in the operation of machines and the construction or processing of aluminum products. The 'others' category included guards, gardeners, shop-persons at the branch factory, and individuals engaged in managing dormitories and catering. Non-manual workers consisted of managers, engineers, clerks, and salesmen, with the remaining individuals (laborers, transport workers, and workers in the 'others' category) considered manual workers.

\section{Baseline examination}

Anthropometric data and biomarkers were obtained from all subjects in 1994. Body weight was measured with the subject wearing light clothing without shoes using a standard scale and height and was measured to the nearest $0.1 \mathrm{~cm}$, without socks, using a stadiometer. Body mass index (BMI) was calculated as weight in kilograms divided by height in meters squared $\left(\mathrm{kg} / \mathrm{m}^{2}\right)$. Systolic blood pressure (SBP) and diastolic blood pressure (DBP) were measured with a mercury sphygmomanometer on the right arm of the subject while he was seated after $5 \mathrm{~min}$ of rest. Mean blood pressure (MBP) was obtained by the formula: $\mathrm{MBP}=(\mathrm{SBP}+\mathrm{DBP} \times 2) / 3$. A fasting blood sample was taken from each subject at least $10 \mathrm{~h}$ after his last meal. Laboratory tests were performed by a laboratory test center. Serum total cholesterol (TCh) and glycated hemoglobin A1c (HbAlc) were measured by enzyme assay and latex agglutination method, respectively.

A self-administered questionnaire was used to collect information concerning working hours, mental and physical work load, and lifestyle, including smoking habits, drinking habits, and leisure time physical activity. Working hours were classified into two groups: $\geq 10 \mathrm{~h}$ and $<10 \mathrm{~h}$ per day. Physical and mental work load were assessed using a single questionnaire and classified into either heavy work or others. Smoking habit was classified into either smoking or non-smoking. Drinking habit was measured by the frequency of drinking per week and classified into two categories: $<5$ times/wk or $\geq 5$ times/wk. Leisure-time physical activity was classified into either lack of regular leisure time physical activity (participation $<1$ time per week) or regular leisure-time physical activity.

\section{Follow-up and endpoint determination}

Incidence of cardiovascular events were ascertained 
until December 2006. Among 1,794 subjects, 1,331 remained in the company and 463 retired or left the factory before the end of the follow-up period. For subjects who stayed with the target company, histories taken at the annual health checkup and medical certification for sickness absence were used for the follow-up. For the 463 retired participants, questionnaires regarding history of cardiovascular events were sent annually by mail. Thirtyone subjects $(6.7 \%)$ were lost from the 463 retired workers or from those who left the factory before the end of follow-up period, including $8.0 \%$ for manual workers and $3.6 \%$ for non-manual workers. In the case of deceased subjects, information was obtained from the subjects' families. To confirm the diagnosis, hospital medical records were reviewed with subjects' consent. For some deceased subjects, death certificates were referenced.

The criteria for MI were modified from those of the WHO (MONICA Project) ${ }^{19)}$. Definite MI was indicated by typical chest pain, with the appearance of abnormal and persistent Q or QS waves, changes in cardiac enzyme activity, or both. Probable MI was indicated by typical chest pain when the findings of electrocardiograms or enzyme activity were not available. Sudden cardiac death was defined as death within $1 \mathrm{~h}$ of onset, a witnessed cardiac arrest, or abrupt collapse.

Stroke was defined as a focal neurological disorder with rapid onset, which persisted at least $24 \mathrm{~h}$ or until death. Stroke events were classified as cerebral hemorrhage, cerebral infarction, or subarachnoid hemorrhage based on computed tomography (CT) and magnetic resonance imaging (MRI). Stroke cases without imaging studies were subclassified according to clinical criteria. The proportion of stroke cases confirmed by $\mathrm{CT}$ and MRI was $91.7 \%$.

Cardiovascular events included stroke, definite or probable MI and sudden cardiac death.

\section{Statistical analysis}

The means of age, BMI, BP, HbAlc, and TCh at the baseline examination were calculated and tested by $t$ test according to occupational category (manual $v s$. non-manual). Smoking habit, drinking habit, and leisure time physical activity were tested by $\chi^{2}$ test according to occupational category. The incidence rates of stroke, MI and cardiovascular events were expressed per 1,000 personyears. The incidence rate and its $95 \%$ confidence interval (CI) were computed by the approximate Poisson Method $^{20)}$. Age-adjusted rates were calculated with indirect methods of standardization using all workers as a standard population. In the multivariate analysis, the hazard ratios and 95\% CI for stroke, MI and cardiovascular events were estimated by the Cox's proportional hazards regression model, after adjusting for confounding factors, including age, BMI, MBP, HbA1c, TCh, smoking, drinking habit, and leisure time physical activity. In the analysis, biological confounding factors were used as continuous variables, irrespective of medication. The analyses were performed using SPSS 16.0 software (SPSS Inc, Chicago, IL, USA) with $p<0.05$ considered statistically significant.

\section{Results}

The total number of subjects and their baseline characteristics by occupational class are shown in Table 1 . There were 632 non-manual workers and 1,162 manual workers. The mean age of the non-manual workers was significantly younger than that of the manual workers. The baseline BMI, SBP, DBP and TCh were similar between the two groups, but the HbAlc level of the manual workers was significantly higher. The difference between non-manual and manual workers with regards to behavioral risk factors, such as smoking and drinking habits, was not significant. The prevalence of lack of regular leisure time physical activity was higher for manual workers than for non-manual workers. The prevalence of long work hours and heavy mental work load were higher for non-manual workers than manual workers.

Table 2 shows the incidence rates of stroke, MI and cardiovascular events combined stroke, MI and sudden cardiac death according to occupational class. In the 12yr follow-up period, there were 60 cardiovascular events, with an incidence rate of 3.14 per 1,000 person-years. The mean follow-up time to an event was $5.6 \mathrm{yr}$. Among these 60 cases, 23 were classified as definite MI and 5 sudden cardiac deaths, and 32 were classified as stroke, including 25 cases of cerebral infarction, 5 cases of cerebral hemorrhage and 2 cases of subarachnoid hemorrhage. There were 23 events (11 stroke, $10 \mathrm{MI}$ and 2 sudden cardiac deaths) in non-manual workers and 37 events (21 stroke, $13 \mathrm{MI}$ and 3 sudden cardiac deaths) in manual workers. For the manual workers, the incidence rate of stroke was similar to non-manual workers, but the incidence rate of MI was lower. All age-adjusted incidence rates of cardiovascular events, stroke, and MI between the two groups were not significantly different.

In Table 3 we show the hazard ratios of the biological factors, health-related behavioral factors and work related factors for stroke, MI and cardiovascular events using the Cox proportional hazards regression model. In the Cox model, age, MBP and HbA1c significantly increased the risk of stroke. BMI and Tch significantly increased the risk of MI. Smoking was suggested as a risk factor for MI. Age, MBP and HbAlc increased the risk of cardiovascular events, and habitual drinking significantly decreased the risk of cardiovascular events and MI. 
Table 1. Baseline characteristics of $\mathbf{1 , 7 9 4}$ male subjects according to occupational class

\begin{tabular}{lcccc}
\hline & & \multicolumn{2}{c}{ Occupational category } & \\
\cline { 3 - 4 } Characteristics & All subjects & $\begin{array}{c}\text { Non-manual } \\
\text { workers }\end{array}$ & $\begin{array}{c}\text { Manual } \\
\text { workers }\end{array}$ & \multirow{2}{*}{$p^{\dagger}$} \\
\hline No. of subjects & 1,794 & 632 & 1,162 \\
Age (yr) & $47.6(4.9)$ & $47.0(4.8)$ & $47.9(5.0)$ & 0.001 \\
Body mass index $\left(\mathrm{kg} / \mathrm{m}^{2}\right)$ & $22.9(2.7)$ & $23.0(2.6)$ & $22.8(2.7)$ & 0.190 \\
Diastolic blood pressure $(\mathrm{mm} \mathrm{Hg})$ & $76.5(11.3)$ & $76.1(11.5)$ & $76.7(11.2)$ & 0.307 \\
Systolic blood pressure $(\mathrm{mm} \mathrm{Hg})$ & $120.4(15.5)$ & $120.2(15.2)$ & $120.4(15.7)$ & 0.788 \\
Mean blood pressure (mm Hg) & $91.1(11.8)$ & $90.8(11.9)$ & $91.3(11.8)$ & 0.443 \\
Glycosylated hemoglobin A1c $(\%)$ & $5.18(0.62)$ & $5.14(0.61)$ & $5.20(0.63)$ & 0.043 \\
Total cholesterol $(\mathrm{mg} / \mathrm{dl})$ & $204.7(34.5)$ & $202.8(33.7)$ & $205.7(35.0)$ & 0.098 \\
Smoking habit $(\mathrm{smokers,} \mathrm{\% )}$ & 58.4 & 58.7 & 58.3 & 0.856 \\
Drinking habit $(\geq 5$ times/wk, \%) & 54.1 & 54.7 & 53.7 & 0.684 \\
Physical activity $(<1$ time/wk, \%) & 57.2 & 51.5 & 60.1 & 0.001 \\
Working hours (more than $10 \mathrm{~h}, \%)$ & 6.3 & 14.1 & 2.3 & 0.000 \\
Physical working load (heavy, \%) & 11.3 & 4.6 & 14.8 & 0.000 \\
Mental working load (heavy, \%) & 21.8 & 27.7 & 18.7 & 0.000 \\
\hline
\end{tabular}

*Values are the means (standard deviations) for continuous variables and percentages for categorical variables.

${ }^{\dagger}$ Significant difference according to Student's $t$ test for means or $\chi^{2}$ test for frequencies.

Table 2. Incidence rate per 1,000 person-years of cardiovascular events, stroke and myocardial infarction during 12-yr follow-up by occupational class

\begin{tabular}{lrrcccc}
\hline & $\mathrm{N}$ & $\begin{array}{l}\text { Person- } \\
\text { years }\end{array}$ & Cases & $\begin{array}{l}\text { Crude } \\
\text { incidence rate }\end{array}$ & $\begin{array}{l}\text { Adjusted } \\
\text { incidence rate }^{\dagger}\end{array}$ & 95\%CI \\
\hline Cardiovascular events & & & & & & \\
$\quad$ All subjects & 1,794 & 19,093 & 60 & 3.14 & - & - \\
$\quad$ Non-manual workers & 632 & 6,600 & 23 & 3.48 & 3.63 & $2.46-5.88$ \\
$\quad$ Manual workers & 1,162 & 12,493 & 37 & 2.96 & 2.90 & $1.81-3.53$ \\
Stroke & 1,794 & 19,093 & 32 & 1.68 & - & - \\
$\quad$ All subjects & 632 & 6,600 & 11 & 1.67 & 1.73 & $0.73-2.85$ \\
$\quad$ Non-manual workers & 1,162 & 12,493 & 21 & 1.68 & 1.65 & $0.92-2.31$ \\
$\quad$ Manual workers & 1,794 & 19,093 & 23 & 1.20 & - & - \\
Myocardial infarction & 632 & 6,600 & 10 & 1.52 & 1.58 & $0.79-3.35$ \\
$\quad$ All subjects & 1,162 & 12,493 & 13 & 1.04 & 1.02 & $0.39-1.33$ \\
$\quad$ Non-manual workers & & & & & & \\
$\quad$ Manual workers & & & & & & \\
\hline
\end{tabular}

CI; confidence interval.

Cardiovascular events: combined stroke, myocardial infarction and sudden cardiac death.

${ }^{\dagger}$ Adjusted for age, calculated by the indirect method of standardization using all workers as a standard population.

Table 4 shows the hazard ratios of stroke, MI and cardiovascular events for manual workers compared to nonmanual workers using the Cox's proportional hazards regression model. In the model, the hazard ratio of cardiovascular events for manual workers compared to nonmanual workers was 0.80 (95\%CI, 0.48-1.35) after adjusting for age alone and 0.92 (95\%CI, 0.53-1.61) after adjusting for age, BMI, MBP, TCh, and $\mathrm{HbAlc}$ and for all confounding factors, including health-related behaviors (smoking, drinking, and leisure time physical activity). The hazard ratio of stroke for manual workers compared to non-manual workers was 0.97 (95\%CI, 0.45-2.08) after adjusting for all confounding factors, including biological factors and health-related behaviors. The hazard ratio of MI for manual workers compared to non-manual workers was 0.73 (95\%CI, 0.30-1.79) after adjusting for all confounding factors, including biological factors and healthrelated behaviors. These results did not change after con- 
Table 3. Relative risk of the biological factors, health-related behavior and work related characteristics for cardiovascular events, stroke and myocardial infarction according to Cox's Proportional Hazards Regression model

\begin{tabular}{|c|c|c|c|c|c|c|c|c|c|c|}
\hline \multirow{2}{*}{ Factor } & \multirow{2}{*}{ Category } & \multicolumn{3}{|c|}{ Cardiovascular events } & \multicolumn{2}{|c|}{ Stroke } & & \multicolumn{2}{|c|}{ MI } & \\
\hline & & HR & $95 \% \mathrm{CI}$ & & HR & $95 \% \mathrm{CI}$ & & $\mathrm{HR}$ & $95 \% \mathrm{CI}$ & \\
\hline Age (yr) & Linear (each 10 increase) & 2.49 & $1.43-4.34$ & * & 3.50 & $1.58-7.77$ & * & 1.48 & $0.61-3.54$ & \\
\hline BMI & Linear (each 1 increase) & 1.04 & $0.95-1.15$ & & 1.00 & $0.87-1.14$ & & 1.17 & $1.00-1.27$ & * \\
\hline $\mathrm{MBP}(\mathrm{mmHg})$ & Linear (each 10 increase) & 1.51 & $1.21-1.88$ & $*$ & 1.82 & $1.36-2.42$ & $*$ & 1.03 & $0.70-1.50$ & \\
\hline TCh (mg/dl) & Linear (each 10 increase) & 1.02 & $0.95-1.10$ & & 0.98 & $0.88-1.08$ & & 1.14 & $1.02-1.27$ & * \\
\hline $\mathrm{HbA1c}(\%)$ & Linear (each 1 increase) & 1.53 & $1.19-1.97$ & $*$ & 1.66 & $1.26-2.19$ & $*$ & 1.34 & $0.77-2.33$ & \\
\hline Smoking habit & smokers vs. nonsmokers & 1.60 & $0.90-2.82$ & & 1.10 & $0.51-2.37$ & & 2.74 & $0.98-7.69$ & + \\
\hline Drinking habit & $\geq 5$ times/wk vs. others & 0.51 & $0.29-0.89$ & * & 0.59 & $0.28-1.25$ & & 0.34 & $0.13-0.89$ & * \\
\hline Physical activity & $<1$ time/wk vs. others & 0.96 & $0.56-1.66$ & & 0.99 & $0.47-2.07$ & & 0.86 & $0.35-2.10$ & \\
\hline Work hours & $\geq 10 \mathrm{~h}$ vs. others & 1.04 & $0.32-3.40$ & & 1.73 & $0.23-13.01$ & & 0.51 & $0.11-2.30$ & \\
\hline Physical workload & Heavy vs. others & 1.25 & $0.47-3.30$ & & 2.04 & $0.45-9.25$ & & 1.80 & $0.23-14.4$ & \\
\hline Mental workload & Heavy vs. others & 0.69 & $0.35-1.34$ & & 0.46 & $0.19-1.11$ & & 1.53 & $0.42-5.57$ & \\
\hline Occupational class & Non-manual vs. manual & 1.00 & $0.56-1.79$ & & 0.88 & $0.39-1.95$ & & 0.78 & $0.32-1.94$ & \\
\hline
\end{tabular}

All factors were put into the model together. ${ }^{*} p<0.01,{ }^{+} p<0.10$.

HR; hazard ratio, CI; confidence interval, HbA1c; glycated hemoglobin A1c, BMI; body mass index, MBP; mean blood pressure, MI; myocardial events, TCh; total cholesterol.

Cardiovascular events: combined stroke, myocardial infarction and sudden cardiac death.

Table 4. Hazard ratios of cardiovascular events, stroke and myocardial infarction by occupational class according to Cox's proportional hazards regression model

\begin{tabular}{|c|c|c|c|c|c|c|}
\hline & \multicolumn{2}{|c|}{ Model 1} & \multicolumn{2}{|c|}{ Model 2} & \multicolumn{2}{|c|}{ Model 3} \\
\hline & HR & $95 \% \mathrm{CI}$ & HR & $95 \% \mathrm{CI}$ & HR & $95 \% \mathrm{CI}$ \\
\hline \multicolumn{7}{|l|}{ Cardiovascular events } \\
\hline Non-manual workers & 1.00 & - & 1.00 & - & 1.00 & - \\
\hline Manual workers & 0.80 & $0.48-1.35$ & 0.79 & $0.47-1.33$ & 0.92 & $0.53-1.61$ \\
\hline \multicolumn{7}{|l|}{ Stroke } \\
\hline Non-manual workers & 1.00 & - & 1.00 & & 1.00 & - \\
\hline Manual workers & 0.94 & $0.45-1.96$ & 0.92 & $0.44-1.93$ & 0.97 & $0.45-2.08$ \\
\hline \multicolumn{7}{|l|}{ Myocardial infarction } \\
\hline Non-manual workers & 1.00 & - & 1.00 & - & 1.00 & - \\
\hline Manual workers & 0.68 & $0.32-14.3$ & 0.66 & $0.29-1.51$ & 0.73 & $0.30-1.79$ \\
\hline
\end{tabular}

$\mathrm{HR}$; relative risk, $\mathrm{CI}$; confidence interval.

Cardiovascular events: combined stroke, myocardial infarction and sudden cardiac death.

Model 1: adjusted for age.

Model 2: adjusted for age (linear), body mass index (linear), mean blood pressure (linear), total cholesterol (linear) and glycated hemoglobin A1c (linear).

Model 3: adjusted for age (linear), body mass index (linear), mean blood pressure (linear), total cholesterol (linear), glycated hemoglobin Alc (linear), and health-related behavior [smoking habit (smokers versus nonsmokers), drinking habit ( $\geq 5$ times/wk versus others), leisure time physical activity ( $<1$ time/wk versus others)].

trolling for work related factors, including working hours and mental and physical work load.

\section{Discussion}

To investigate whether a relationship between occupational class and cardiovascular events exists in Japan as compared to other industrialized nations, we conducted a prospective, 12-yr follow-up study of a group of male fac- tory employees. Incidence rates were $1.68 / 1,000$ personyear for stroke and 1.20/1,000 person-year for MI among all subjects. These rates approximated the rates from other Japanese study populations, such as men in Osaka aged 40-69 (stroke 1.18/1,000 person-year; MI 0.9/1,000 person-year) and men in Akita aged 40-69 (stroke 2.31/1,000 person-year; MI 0.51/1,000 person-year ${ }^{21)}$. If we compare the data for the same age group, the incidence rates in our subjects are higher compared to these 
other two geographic areas.

In the present study, manual workers did not show a significant increase in the risk of cardiovascular events compared to non-manual workers. The incidence rate of stroke in both groups was almost identical. The incidence rate of MI in manual workers was lower compared to nonmanual workers, but no significant difference was found. Also, the results did not differ after adjusting for behavioral or biological risk factors. Analysis was also performed after sub-categorization of the non-manual workers into two groups; that is, either managers and engineers $(n=411)$ or clerical and sales workers $(n=221)$. We did not find a significantly higher risk of cardiovascular events for manual workers compared with managers and engineers or clerical and sales workers (data not shown). These findings are in disagreement with many studies from other industrialized countries. Stroke mortality and incidence rate of manual workers were significantly higher than those of non-manual workers in European countries and US ${ }^{1,2,4,7,9)}$, although a north-south gradient was observed for ischemic heart disease; mortality from ischemic heart disease was strongly related to occupational class in England and Wales, Ireland, Finland, Sweden, Norway and Denmark, but not in France, Switzerland, Spain and Portugal ${ }^{11}$.

Other studies have attempted to explain the health inequalities regarding cardiovascular diseases by differences in health behaviors or biological risk factors $6,8,10,11$. These studies showed that members of the manual class had higher blood pressure levels, higher BMI, and increased prevalence of current cigarette smoking. However, we did not find significant differences in those risk factors at baseline between the two groups, except for HbAlc and leisure time physical activity. In a comparative study on socioeconomic differences in behavioral and biomedical risk factors in a Japanese and English cohort of employed men, it was found that higher employment grades in Japan had higher BMI and waist-to-hipratios and lower high-density lipoprotein cholesterol levels, while the opposite associations were found among men in England ${ }^{22,23)}$. These results were validated by another study in Japan, using educational background as a socioeconomic factor in the study ${ }^{24)}$. A health management system, including health check-ups and a followup system to prevent work-related diseases, including cardiovascular disease, was developed based on labor laws enacted in Japan ${ }^{25}$. All workers, particularly those in large enterprises, receive equal benefits from this system regardless of their occupational class. This might partially contribute to the lack of inequality among the traditional risk factors and incidence of cardiovascular events by occupational classes in our subjects.

Psychosocial factors were also considered as con- tributing to the inequalities between occupational classes and employment grades as they relate to cardiovascular diseases $^{7,12)}$. Researchers found that the lower employment grades suffered more psychosocial distress. We used a simple questionnaire asking for a self-estimation of mental load and work hours instead of the established questionnaires normally used to detect job psychosocial distress. Non-manual workers worked more hours and felt more mental load compared with manual workers. It appeared that the psychosocial distress of manual workers was not higher than non-manual workers.

Our study has several limitations. Our subjects were recruited in one workplace. Our results may therefore reflect the tendency of subjects in a stable and favorable workplace environment. Since there has been little previous research on this topic, more studies are required. In addition, the problem of statistical power due to small sample size cannot be ignored. In addition, our followup period may have been too short to acquire an adequate number of subjects in the age range of 40-59. However, the traditional cardiovascular risk factors were determined as significant risks in this study. Therefore, we can say that occupational class did not affect the onset of cardiovascular events to the same degree as the traditional risk factors. Since the mean age of our non-manual workers was younger than that of our manual workers, we may have underestimated the incidence rates of cardiovascular events in non-manual workers even after age adjustment. This could potentially mask inequalities in cardiovascular events between occupational classes, which is opposite to the findings of other industrialized countries. Finally, some might query whether the difference in occupational class contained socioeconomic aspects. We analysed the employment grade after $6 \mathrm{yr}$ from baseline for 1,783 subjects. Our data revealed that there was a significant difference in employment grade between the two groups; $42.7 \%$ of non-manual workers were of managerial or administrative rank, compared to only $5.1 \%$ of manual workers. Therefore, the occupational category was considered to reflect employment grade.

In conclusion, our findings do not indicate an elevated risk for the development of cardiovascular events in manual workers when compared to non-manual workers in a large-scale factory in Japan. These findings are not in accordance with many studies from other industrialized countries.

\section{Acknowledgements}

This work was supported by the Japan Arteriosclerosis Prevention Fund; and the Ministry of Health, Labor and Welfare, Health and Labor Sciences Research Grants, Japan (Comprehensive Research on Cardiovascular and Life-style Related Diseases: H20-Ippan-013). 


\section{References}

1) Kunst AE, Groenhof F, Mackenbach JP, the EU Working Group on Socioeconomic Inequalities in Health (1998) Occupational class and cause specific mortality in middle aged men in 11 European countries: comparison of population based studies. BMJ 316, 1636-42.

2) Kunst AE, del Rios M, Groenhof F, Mackenbach JP for the European Union Group on Socioeconomic Inequalities in Health (1998) Socioeconomic inequalities in stroke mortality among middle-aged men: an international overview. Stroke 29, 2285-91.

3) Hallqvist J, Lundberg M, Diderichsen F, Ahlbom A (1998) Socioeconomic differences in risk of myocardial infarction 1971-1994 in Sweden: time trends, relative risks and population attributable risks. Int $\mathrm{J}$ Epidemiol 27, 410-5.

4) Hart CL, Hole DJ, Smith GD (2000) Influence of socioeconomic circumstances in early and later life on stroke risk among men in a Scottish cohort study. Stroke 31, 2093-7.

5) Smith GD, Hart C, Blane D, Gillis C, Hawthorne V (1997) Lifetime socioeconomic position and mortality: prospective observational study. BMJ 314, 547-52.

6) Suadicani P, Hein HO, Gyntelberg F (2001) Socioeconomic status and ischaemic heart disease mortality in middle-aged men: importance of the duration of follow-up. The Copenhagen Male Study. Int J Epidemiol 30, 248-55.

7) Virtanen SV, Notkola V (2002) Socioeconomic inequalities in cardiovascular mortality and the role of work: a register study of Finnish men. Int J Epidemiol 31, 614-21.

8) Emberson JR, Whincup PH, Morris RW, Morris RW, Walker (2004) Social class differences in coronary heart disease in middle-aged British men: implications for prevention. Int J Epidemiol 33, 289-96.

9) Mackenbach JP, Bos V, Andersen O, Cardano M, Costa G, Harding S, Reid A, Hemström Ö, Valkonen T, Kunst AE (2003) Widening socioeconomic inequalities in mortality in six Western European countries. Int J Epidemiol 32, 830-7.

10) Marmot MG, Rose G, Shipley M, Hamilton PJS (1978) Employment grade and coronary heart disease in British civil servants. JECH 32, 244-9.

11) Marmot MG, Smith GD, Patel C, Stansfeld S, North F, Head J, White I, Brunner E, Feeney A (1991) Health inequalities among British civil servants: the Whitehall II study. Lancet 337, 1387-93.

12) Marmot MG, Bosma $H$, Hemingway $H$, Brunner $E$, Stansfeld S (1997) Contribution of job control and other risk factors to social variations in coronary heart disease incidence. Lancet 350, 235-9.

13) NIPPON DATA80 Research Group (2003) Impact of elevated blood pressure on mortality from all causes, cardiovascular diseases, heart disease and stroke among
Japanese: 14 year follow-up randomly selected population from Japanese (NIPPON Data80). J Hum Hypertens 17, 851-7.

14) Okamura $T$, Kadowaki $T$, Hayakawa $T$, Kita $Y$, Okayama A, Ueshima H, NIPPON DATA80 Research Group (2003) What cause of mortality can we predict by cholesterol screening in the Japanese general population? J Intern Med 253, 169-80.

15) Ueshima H, Choudhury SR, Okayama A, Hayakawa T, Kita Y, Kadowaki T, Okamura T, Minowa M, Iimura O, NIPPON DATA80 Research Group (2004) Cigarette smoking as a risk factor for stroke death in Japan. Stroke 35, 1836-41.

16) Iso $H$, Imano $H$, Kitamura $A$, Sato $S$, Naito $Y$, Tanigawa T, Ohira T, Yamaguchi K, Iida M, Shimamoto T (2004) Type 2 diabetes and risk of non-embolic ischaemic stroke in Japanese men and women. Diabetologia 47, 2137-44.

17) Fujino $Y$, Iso $H$, Tamakoshi $A$, Inaba $Y$, Koizumi A, Kubo T, Yoshimura T for the JACC Study Group (2005) A prospective cohort study of employment status and mortality from circulatory disorders among Japanese workers. J Occup Health 47, 510-7.

18) Statistics Bureau, Director-general for policy planning \& Statistical Research and Training Institute, Ministry of Internal Affairs and Communications. Japan Standard Occupational Classification. http://www.stat.go.jp/english/ index/seido/shokgyou. Accessed January 28, 2009.

19) WHO MONICA project (1990) MONICA Manual, revised Ed., Cardiovascular Diseases Unit, WHO, Geneva.

20) Kahn HA, Sempos CT (1989) Statistical methods in Epidemiology. Oxford University Press, New York.

21) Kitamura A, Sato S, Kiyama M, Imano H, Iso H, Okada T, Ohira T, Tanigawa T, Yamagishi K, Nakamura M, Konishi M, Shimamoto T, Iida M, Komachi Y (2008) Trends in the incidence of coronary heart disease and stroke and their risk factors in Japan, 1964 to 2003. JACC 52, 71-9.

22) Martikainen $P$, Ishizaki M, Marmot MG, Nakagawa $H$, Kagamimori S (2001) Socioeconomic differences in behavioural and biological risk factors: a comparison of a Japanese and an English cohort of employed men. Int J Epidemiol 30, 833-8.

23) Ishizaki M, Yamada Y, Morikawa Y, Noborizaka Y, Ishida M, Miura K, Nakagawa H (1999) The relationship between waist-to-hip ratio and occupational status and life-style factors among middle-aged male and female Japanese workers. Occup Med 49, 177-82.

24) Anzai $Y$, Ohkubo $T$, Nishino $Y$, Tsuji I, Hisamichi $S$ (2000) Relationship between health practices and education level in the rural Japanese population. J Epidemiol 10, 149-56.

25) Ministry of Health, Labour and Welfare, Japan. Industrial Safety and Health Act (Act No. 57 of 1972), Ministry of Health, Labour and Welfare, Tokyo. 